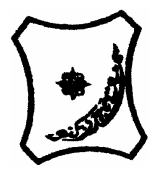

Bayero Journal of Pure and Applied Sciences, 4(2): 5 - 11

Received: April, 2011

Accepted: August, 2011

ISSN $2006-6996$

\title{
ROSIGLITAZONE AND CARDIOVASCULAR RISK - A REVIEW
}

Suleiman Isa,

Department of Biomedical Sciences, University of Wales Institute Cardiff, UK

\begin{abstract}
The thiazolidinediones (TZDS) are a class of oral drugs used for the management of type 2 diabetes mellitus and act as ligands for the transcription factor Peroxisome Proliferator-Activated Receptor gamma (PPARY). Rosiglitazone, an example of TZD, is an anti-diabetic agent acting as a potent insulin sensitizer and is used clinically to enhance insulin-stimulated glucose uptake in tissues. However, in spite of the beneficial effects of TZDs in management of type 2 diabetes, the safety of rosiglitazone has recently been called into question. The debate about the risks associated with rosiglitazone therapy heightened in 2007, when it was reported that rosiglitazone was associated with an increase risk of myocardial infarction and death from cardiovascular causes. The cardiovascular risk associated with rosiglitazone use remains to be further elucidated, but there are several reasonable hypotheses.
\end{abstract}

Keywords: Thiazolidinediones; Rosiglitazone; Type 2 Diabetes; Cardiovascular risk

INTRODUCTION

Type 2 diabetes (T2D) is the most common metabolic disorder worldwide (Goldstein, 2003); its pathogenesis involves insufficient insulin secretion and/or resistance to the action of insulin. Insulin resistance results in decreased glucose uptake by the peripheral tissues while glucose production by the liver is increased. High levels of insulin production as a result of insulin resistance lead to high levels of insulin in the blood, a condition called hyperinsulinaemia. When insulin production reaches a peak, such high levels of insulin are not sustainable and ultimately $\beta$-cell insulin secretion fails. This leads to loss of glycemic control, and hence full-blown T2D. There is an increasing evidence of T2D in almost every population worldwide and epidemiological studies suggests that without proper prevention and control programmes, prevalence of the disease will continue to increase globally (Alberti et al., 2007).

Thiazolidinediones (TZDs) are a class of oral drugs used for the treatment of T2D. TZDs were discovered as a result of screening of compounds with lipid-lowering capacity and were noted to reduce hyperglycemia and hyperinsulinemia in rodent models of insulin resistance (IR) (Lebovitz and Banerji, 2001). At around the same time, the mechanism of action of TZDs was found to involve interaction with the transcription factor PPARY, binding of the resultant complex to the PPARy response element within the promoter of PPARy target genes, and thus regulation of the expression of genes that play a role in lipid and glucose metabolism (Olefsky, 2000). TZDs that have been extensively studied in animal and human models include Troglitazone, Rosiglitazone and Pioglitazone. Troglitazone was the first TZD to be introduced, however because of its association with liver damage it was removed from the market in March 2000 (Gale, 2001), while rosiglitazone and pioglitazone were approved for clinical use in 1999 (Lebovitz and Banerji, 2001).
Type 2 Diabetes and its Complications

The major chronic complications of diabetes are cardiovascular diseases (CVD), neuropathy, nephropathy, amputation and retinopathy (IDF, 2009). There is clear evidence of the promoting impact of diabetes on the prevalence, severity and prognosis of CVD. A study however, has shown a consistent relationship between hyperglycemia and CVD (Balku et al., 2004). Moreover, CVD is the major cause of death in diabetes accounting for $50 \%$ or more of all diabetes burdens (IDF, 2009).

Levels of obesity are rapidly growing in both developed and developing countries. According to the Obesity Task Force and the WHO world report of 2002, about $58 \%$ of diabetes globally can be attributed to body mass index (BMI) above $21 \mathrm{~kg} / \mathrm{m}^{2}$ (WHO, 2002). Waist-to-hip ratio (waist circumference) also plays an important role as a risk factor for type 2 diabetes. Rexrode et al., (1998), showed that waist circumference, which reflects abdominal fat, may be a better indicator of the risk of developing T2D than the BMI. Furthermore, Stein and Colditz (2004) showed that approximately $80 \%$ cases of T2D could be attributed to a combination of inactivity and high body weight.

Obesity is also associated with CVD. It has been estimated that $20-30 \%$ mortality due to CVD may be attributed to excess body weight (Seidell et al., 1996). The risk of developing T2D is almost 10 times greater in obese individuals compared with nonobese individuals (Chang et al., 1994; Colditz et al., 1995). Obesity and being overweight is also associated with adiposity (the portion of total body mass that is comprised of neutral lipid deposits in adipose tissues). A strong correlation has been shown to exist between adiposity and insulin resistance leading to T2D (Tai et al., 2000; Janssen et al., 2002; Kahn et al., 2006). Thus, T2D and its complications pose serious threat worldwide. 
The negative impact of the high prevalence rate of T2D is associated with morbidity and mortality, as well as considerable public cost (Davis et al., 2006; Yach et al., 2006).

\section{Thiazolidinediones for the Treatment of Type 2 Diabetes}

As mentioned earlier, TZDs are a class of oral drugs used for the treatment of T2D. TZDs have been shown to enhance the ability of insulin to promote glucose transport into skeletal muscles and therefore lower glucose levels in the blood (Olefsky and Saltiel, 2000), and decrease hepatic glucose production (Maggs et al., 1998) while prolonging pancreatic $\beta$-cell function by preventing $\beta$-cells apoptosis (Higa et al., 1999). With regard to the other component of the metabolic syndrome, TZDs play a role in blood pressure regulation, vascular tone and endothelial function, all of which might directly and/or indirectly influence cardiovascular disease (St John et al., 2002; Mudaliar, 2007). Enhancement of fibrinolytic activity system as a result of TZD treatment has also been shown in patients with type 2 diabetes (Kruszynska et al., 2000). TZDs' other vascular effects include their ability to reduce the expression of endothelial adhesion molecules thereby limiting smooth muscle cell activation (Marx et al., 2001), while other important cardiovascular effects of TZDs include their ability to reduce elevated plasma triglycerides, increase plasma HDL cholesterol and decrease LDL cholesterol/HDL cholesterol ratio (Lebovitz and Banerji, 2001). Other studies suggested that TZDs could stimulate adipocyte differentiation and generate small adipocytes that are more insulin-sensitive than large adipocytes (Kahn et al., 2000). Consequently, TZDs may also have the potential to reduce visceral obesity, low-grade inflammation and microalbuminuria in patients with metabolic syndrome (Viberti, 2005).

Despite the aforementioned beneficial effects of TZDs as anti-diabetic agents, several studies have shown that they have adverse side effects. Weight gain due to fluid retention or oedema is among the adverse side effects of TZDs treatment (Lebovitz and Banerji, 2001). Inhibition of vascular smooth muscles and endothelial cells growth and migration has also been attributed to TZDs treatment (Hsueh and Law, 2001). In addition, risk of congestive heart failure limit the use of TZDs as first line treatment in diabetics (Nathan et al., 2006). However, TZDs have also been shown to increase the risk of myocardial infarction and death from cardiovascular causes (Nissen and Wolski, 2007) although this has been contradicted by other study (Singh et al., 2007). The effect of TZDs on negative cardiovascular effects will be discussed in subsequent section.

\section{Peroxisome Proliferator-Activated Receptors (PPARs)}

Peroxisome Proliferator-Activated Receptors (PPARs) are ligand-activated transcription factors that belong to the nuclear receptor super family. They are activated by specific ligands that play an important role in cell signalling. For more than a decade, PPARs have been extensively studied and shown to participate in maintenance of glucose and lipid homeostasis, differentiation and cellular proliferation (Delerive et al., 2001). The PPARs consists of three isotypes: alpha (NR1C1), gamma (NR1C3) and beta/delta (NRC1C2) (Cabrero et al., 2002). These three isoforms of PPAR are encoded by separate genes that perform different functions and are expressed in different manner in different tissues. PPAR alpha is highly expressed in liver, muscle, kidney and heart, where it stimulates the beta-oxidative degradation of fatty acids (Chinetti et al., 2000). PPAR gamma is mainly expressed in monocytes/macrophages, endothelial cells, smooth muscle cells, intestine and adipose tissues where it triggers adipocyte differentiation and promote lipid storage (Chinetti et al., 2000). PPARbeta is ubiquitously expressed in vascular cells. Transcriptional activation of PPARs involves heterodimerization with retinoid-X-receptor (RXR). The dimer binds to related DNA elements called PPAR response elements (PPRE) in the $5^{1}$ - flanking region of target genes (Evan and Bruce, 2001).

\section{PPARY}

Due to its broad range of physiological roles, PPARY is the most extensively studied isoform of PPARs. In humans, PPARy gene is located on chromosome $3 \mathrm{p} 25$ having 9 exons and extends over more than $100 \mathrm{~kb}$ of the genome. PPARY has three different protein isoforms: PPAR $y_{1}, \mathrm{PPAR}_{2}$, and PPAR $y_{3}$. The $\mathrm{N}$ terminus of PPAR $\gamma_{2}$ contains 30 additional amino acids compared to PPAR $y_{1}$ (Tontonoz et al., 1994). Most tissues however, have relatively low levels of PPAR $\gamma_{1}$. Although PPAR $\gamma_{2}$ and $\mathrm{PPAR}_{3}$ are expressed in adipose tissues, PPAR $y_{2}$ is expressed at higher levels. Studies have shown that PPARy plays a vital role in cellular differentiation, insulin sensitivity, atherosclerosis and cancer. Apart from its effects in glucose homeostasis, PPARy has also been shown to have other diverse metabolic and cardiovascular effects (Hsueh and Bruemmer, 2004). However, because of its actions to improve insulin sensitivity, most researches focused on PPARy.

Several synthetic and naturally occurring compounds have been shown to bind to and activate PPARs. These synthetic ligands were shown to have high affinity for PPARy. TZDs are one such ligands. TZDs bind directly to the ligand-binding domain of PPARY but not PPARa or PPARס, and hence function as receptor agonists (Smith, 2003). Other synthetic PPARy ligands include triterpinoid [2-cyano-3,12divoaleana-1,9-diene-28-oic acid] (Suh et al., 1999) and aryl-tyrosine derivatives (Evan and Bruce, 2001). On the other hand, natural compounds such as fatty acids, eicosanoids and oxidized fatty acids are also shown to activate PPARs (Kliewer et al., 1995; Nagy et al., 1998).

\section{Rosiglitazone for the Treatment of Type 2} Diabetes

Marketed by GlaxoSmithKline, Rosiglitazone is one of the anti-diabetic agents of the TZD class of antihyperglycemic drugs. 
Currently, the drug exists in three different forms: Avandia (monotheraphy), Avandamet (combination product containing rosiglitazone and metformin) and Avandaryl (combination product containing rosiglitazone and glimepiride). Rosiglitazone is a potent insulin sensitizer clinically used to enhance insulin stimulated glucose uptake by tissues and has been shown to restore normal insulin secretion in individuals with impaired glucose tolerance (Juhl et al., 2003). Addition of rosiglitazone to insulin treatment significantly improves glycemic control and was generally tolerated by diabetic patients (Raskin et al., 2001). Other studies showed that rosiglitazone could have effect on calcium signalling by affecting monocytic calcium signalling processes which may give a level of guard against diabetic microangiopathy (Atkin, 2008). Platelets of type 2 diabetics showed significant hyperaggregability and increased thrombogenic potential (Watala et al., 2005). However, treatment with rosiglitazone increased platelet SERCA2 expression and $\mathrm{Ca}^{2+}$-ATPase activity, decreased SERCA2 tyrosine nitration and normalized platelet intracellular calcium concentration (Randriamboavonjv et al., 2008). Rosiglitazone has also been shown to reduce MMP-9 serum levels in type 2 diabetic patients with coronary artery disease (Marx et al., 2003). MMPs are shown to be involved in the development of unstable plaques of arteriosclerotic lesions in patients with type 2 diabetes mellitus (Marx et al., 2003). Overall, the importance of rosiglitazone in the management of type 2 diabetes is well established.

\section{Rosiglitazone and Negative Cardiac Outcome}

The ability of rosiglitazone to reduce blood glucose and glycated haemoglobin levels in patient with type 2 diabetes was the basis of its approval. However, there has been considerable increase in debate regarding the risks and benefits of its use to treat diabetes. Meta-analysis by Nissen and Wolski suggested that rosiglitazone treatment is associated with a significant increase in the risk of myocardial infarction and with a borderline significant increase in the risk of death from cardiovascular causes (Nissen and Wolski, 2007). Nissen and Wolski's meta-analysis was primarily based on small-scale short-term trials that were not intended to ascertain cardiovascular outcomes (Nissen and Wolski, 2007), nevertheless the study highlighted the urgent need for clarification of the role of rosiglitazone in increasing cardiovascular risk. In a related development, the rosiglitazone evaluated for cardiovascular outcome and regulation of glycaemia in diabetes (RECORD) interim analysis (Home et al., 2007) showed no evidence of any increase in cardiovascular or all-cause mortality. However the study found an increased risk of heart failure associated with rosiglitazone treatment (Home et al., 2007). Another meta-analysis by Singh et al., (2007) showed that 12 months of rosiglitazone administration in patients with impaired glucose tolerance or T2D is associated with a significant increase in risk of myocardial infarction and heart failure without a significant increase in the risk of cardiovascular mortality. On the other hand, more recent studies have held up the view that rosiglitazone should be used only alongside stronger warnings together with the use of informed consent (Rosen, 2010). However, it is important to note that in none of these studies was the mechanism by which rosiglitazone may cause the risk of death from cardiovascular causes (Nissen and Woslki, 2007), myocardial infarction and heart failure (Home et al., 2007; Singh et al., 2007) was elucidated.

Besides the negative cardiac outcomes associated with rosiglitazone therapy, other detrimental side effects of rosiglitazone therapy include weight gain, increase in plasma volume, edema and increased plasma LDLcholesterol concentration appear to be the classical effects of TZDs (Lebovitz and Banerji, 2001). As reported by Soroceanu et al, (2004) rosiglitazone impacts negatively on bone remodelling by promoting osteoblast and osteocyte apoptosis (Soroceanu et al., 2004). Rosiglitazone is also associated with reductions in markers of bone formation and reductions in bone mineral density (Grey et al., 2007).

\section{Rosiglitazone and Calcium Homeostasis}

Due to the cardiac problems associated with rosiglitazone, and the links between hypertension, cardiac dysfunction, microvascular diabetic complications (Advani et al., 2004; Belke et al., 2004; Singh et al., 2005) and disruptions in $\mathrm{Ca}^{2+}$ homeostasis, the effects of rosiglitazone on $\mathrm{Ca}^{2+}$ homeostasis within monocytes and cardiomyocytes take on increased importance. A small number of studies have shown that rosiglitazone can cause disruption in $\mathrm{Ca}^{2+}$ homeostasis. For example, treatment of cardiomyocytes with $10 \mu \mathrm{M}$ rosglitazone upregulates the calcium pump enzyme of cardiomyocytes, sarco-endoplasmic reticulum ATPase (SERCA2a) and bring about altered intracellular calcium handling (Shah et al., 2004). In a related development, Randriamboavonjy et al., (2008) also demonstrated that treatment of megakaryocytes and platelets with rosiglitazone upregulates SERCA2b.

\section{Molecular Mechanism of Rosiglitazone-Induced Cardiac Failure}

Study within our research group had shown that rosiglitazone could induce the unfolded protein response (UPRs) in vascular smooth muscle cells (VSMC) and monocytes, but that this did not lead to cytotoxic apoptosis effects in these cells (Caddy et al., 2010). We also showed that rosiglitazone-induced upregulation of UPR target genes in monocytes and VSMC was sufficient to restore normal cell physiology and prove not to be cytotoxic in those cells. However, as the safety concerns reported for rosiglitazone apply specifically to negative cardiac outcomes (Nissen and Wolski, 2007; Rosen 2010), we extended these observation to cardiomyocytes (Isa, 2011) by investigating the effects of rosiglitazone on $\mathrm{Ca}^{2+}$ homeostasis, endoplasmic reticulum (ER) stress and cell viability and apoptosis in in vitro model system for cardiomyocytes (HL-1 cells). 
The ER performs several important functions including post-translational modification, folding and assembly of newly synthesized secretory proteins and calcium homeostasis. Disturbing any of the ER functions may lead to imbalance between protein-folding load and the capacity of the ER, causing unfolded or misfolded proteins to accumulate in the ER lumen, a condition referred to as ER stress (Araki et al., 2003; Zhang and Kaufman, 2008). Cells have evolved a protective response to deal with the deleterious effects of ER stress called UPR (Patil and Walter, 2001; Ron and Walter, 2007) that aims to restore normal ER function, or lead to apoptotic cell death in conditions of prolonged ER stress (Szegezdi et al., 2006). [ $\left.\mathrm{Ca}^{2+}\right]_{\mathrm{cyt}}$ is tightly regulated for normal cell physiology. Factors that can interfere with calcium signalling processes may induce cell death by apoptosis (Kass and Orrenius, 1999). In addition, ER stress-related genes have been previously shown to be induced in samples of human and mouse heart failure, suggesting that ER stress may be involved in the pathogenesis and the development of heart failure (Okada et al., 2004). Thus, we hypothesised that rosiglitazone by interfering with ER calcium homeostasis can induce ER stress and UPR in HL-1 cardiomyocytes.

To test our hypothesis, the consequent effects of rosiglitazone on apoptosis were examined. Furthermore the induction of different transcription factors involved in ER stress and UPR following rosiglitazone treatment of $\mathrm{HL}-1$ cells were also investigated. The rosiglitazone concentrations selected are within the range the drug has been shown to exert molecular effects in myocytes of neonatal rat ventricles (Shah et al., 2004) and in monocytes (Caddy et al., 2008) and comparable to those approximating its pharmacological levels (Niemi et al., 2003). Treatment of $\mathrm{HL}-1$ cells with rosiglitazone was associated with a significant increase in apoptosis and with a significant decrease in cell viability (Isa, 2011). Given that rosiglitazone causes significant cardiomyocyte apoptotic cell death (figure 1), it is important to elucidate the mechanisms by which rosiglitazone treatment may result in cardiomyocyte apoptosis. Thus we elucidated the mechanism as being induction of ER stress and UPR (Isa, 2011).

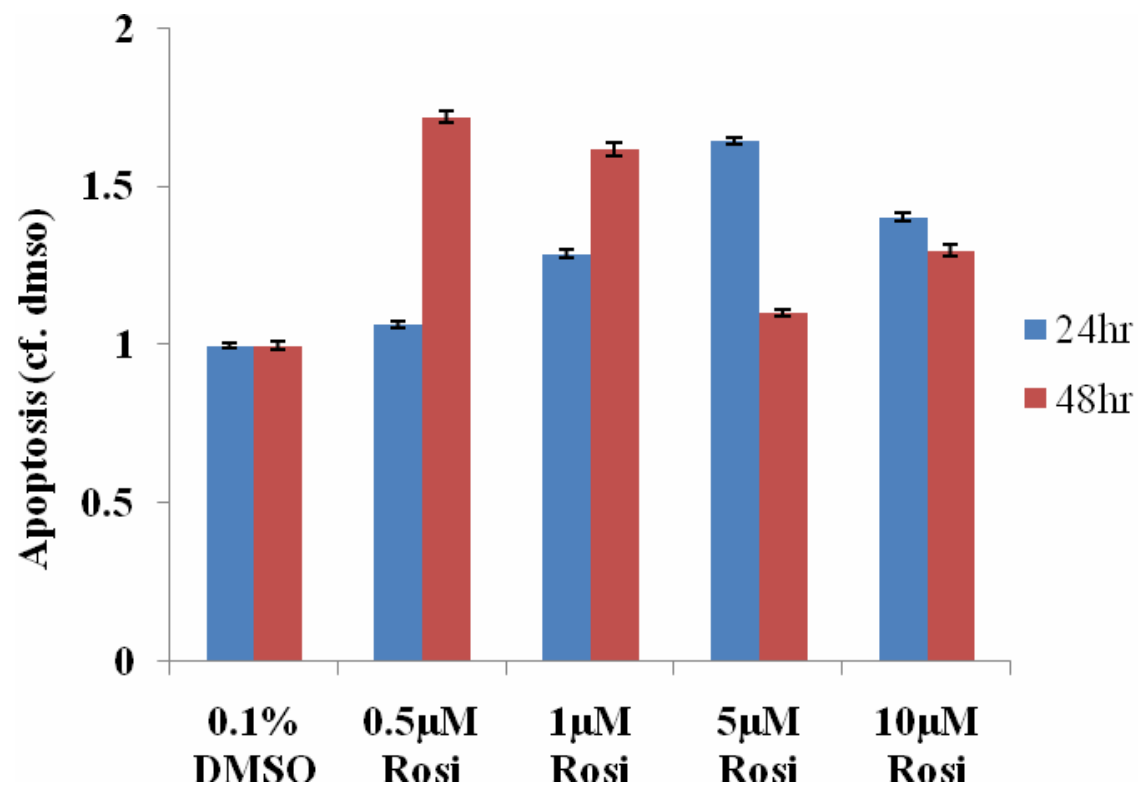

Figure 1: The effects of treatment with dmso $(0.1 \%)$ or rosiglitazone $(0.5$ to $10 \mu \mathrm{M})$ on $\mathrm{HL}-1$ cells apoptosis ( $P<0.05$ in all cases) (Isa, 2011).

To further investigate the fact that ER stress is involved in rosiglitazone-induced apoptosis in cardiomyocytes, C/EBP homologous protein ( $\mathrm{CHOP}$ ) was investigated. $\mathrm{CHOP}$ is an important UPR gene that is barely detected under physiological conditions in proliferating cells but is upregulated in response to growth arrest signals and ER stress (Hotamisligil, 2005). Importantly CHOP is found to be induced in failing heart and cardiomyocytes apoptosis during the progression from cardiac hypertrophy to heart failure (Okada et al., 2004). We showed that CHOP mRNA is upregulated following rosiglitazone treatment of $\mathrm{HL}-1$ cells (Isa, 2011). Upregulation of CHOP mRNA (Figure 2) strongly suggests that rosiglitazone treatment is associated with ER stress. 


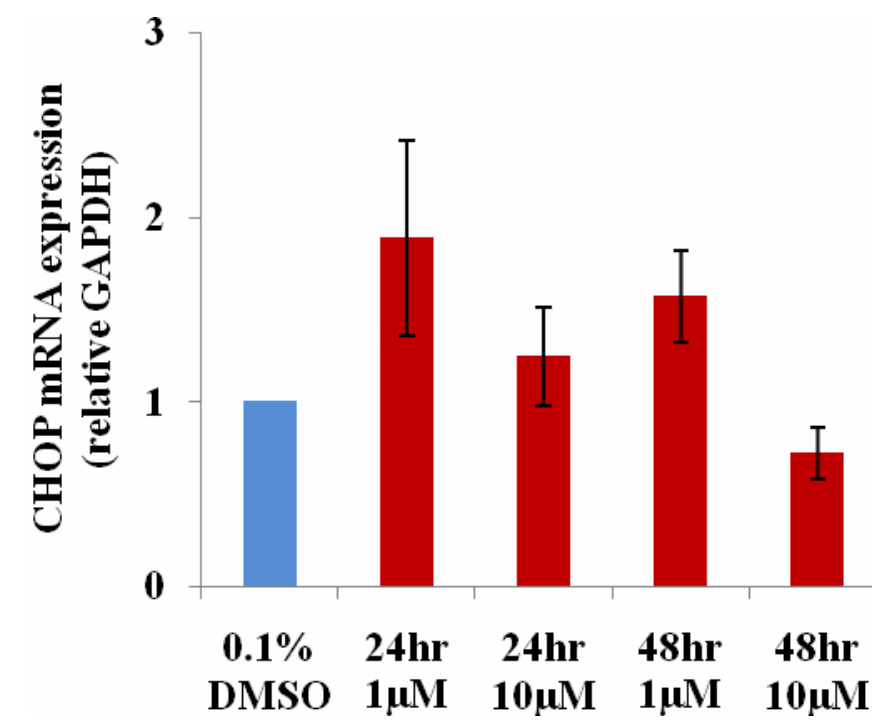

Figure 2: The effects of treatment with dmso $(0.1 \%)$ or rosiglitazone (1 to $10 \mu \mathrm{M})$ on HL-1 cells apoptosis on CHOP mRNA expression in HL-1 cells (Isa, 2011).

\section{CONCLUSION}

As reviewed by Kang and Izumo (2000), the etiology of heart failure involves numerous conditions but progressive loss of cardiac myocytes is largely the most significant. Myocytes apoptosis occurs during heart failure and may play a significant role in the development of heart failure. Apoptosis may perhaps cause cardiac dysfunction by numerous mechanisms. For example, loss of cardiomyocytes by apoptosis leads to loss of cardiac mass and cardiac remodelling as a result of alteration of neighbouring cardiomyocytes. Thus, it may be envisaged that the

\section{REFERENCES}

Advani, A., Marshall, S.M., and Thomas T.H. (2004). Impaired Neutrophil Store-Mediated Calcium Entry in Type 2 Diabetes. European Journal of Clinical Investigation 34:43-49

Alberti, K.G., Zimmet, P., and Shaw, J. (2007). International Diabetes Federation: A Consensus on Type 2 Diabetes Prevention. Diabet. Med. 24(5)451-463

Araki, E., Oyadomari, S., and Mori, M. (2003). Impact of endoplasmic reticulum stress pathway on pancreatic $\beta$-cells and diabetes mellitus. Exp. Biol. Med. 228(10): 1213-1217

Atkin, L. (2008). Rosiglitazone Induced SERCA2b Inhibition: Implications for Monocyte Cytoskeletal Remodeling and Diabetic Microangiopathy. Bioscience Horizons 1(1):1-8

Balku, B., Hu, G., Qiao, Q., Tuomilehto, J., BorchJohnsen, K., and Pyoraja, K. (2004). Prediction of the Risk of Cardiovascular Mortality Using a Score that Includes Glucose as a risk factor. The DECODE study. Diabetologia 47(12):2118-2128

Belke, DD., Swanson, E.A., and Dilmann, W.H., (2004). Decreased sarcoplasmic reticulum activity in diabeticdb/db mouse heart Diabetes 53(12)3201-3208.

Cabrero, A., Laguna, J.C., and Vazquez, M. (2002). Pereoxisome Proliferator-activated Receptors and loss of cardiac mass as a result of apoptosis may lead to diminished pump power and disturbance in electric conductance that may also lead to arrhythmias. In view of our understanding that rosiglitazone causes significant cardiomyocytes apoptosis (Isa, 2011), we suggest that our study might help to explain why the interim meta-analysis of Nissen and Wolski (2007), the RECORD study and Singh et al's (2007) metaanalysis all reported negative cardiovascular events (particularly heart failure) associated with rosiglitazone therapy.

Control of Inflammation. Curr. Drug. Targets. Inflamm. Allergy 1(3):243-248

Caddy, J., Isa, S., Mainwaring, L.S., Adam, E., Roberts, A., Lang, D., Morris, R.H.K., Thomas, A.W., and Webb, R. (2010). Rosiglitazone induces the unfolded protein response but has no significant effect on cell viability in monocytic and vascular smooth muscle cells. Biochem. Biophys. Res. Commun. 400:689-695

Caddy, J., Singh, N., Atkin, L., Ahluwalia, M., Roberts, A., Lang, D., Thomas, A.W., and Webb, R. (2008). Rosiglitazone Transciently Disturbs Calcium Homeostasis in Monocytic Cells. Biochem. Biophys. Res. Commun 366(1):149-155

Chinetti, G., Fruchart, J.C., and Staels, B. (2000). Pereoxisome Proliferator-activated Receptors (PPARs): Nuclear Receptors at the Crossroads Between Lipid Metabolism and Inflammation. Inflamm. Res. 49(10):497-505

Colditz, G.A., Willett, W.C., Rotnitzky, A., and Manson, J.E. (1995). Weight Gain as a Risk Factor for Clinical Diabetes Mellitus in Women Ann. Intern. Med. 122(7):481-486

Chang, J.M., Rimm, E.B., Colditz, G.A., Stampfer, M.J., and Willett, W.C. (1994). Obesity, Fat Distribution and Weight Gain as Risk Factors for Clinical Diabetes in Men. Diabetes Care 17(9):961-969 
Davis, W.A., Knuiman, M.W., Hendrie, D., and Davis, T.M. (2006). The Obesity Driven Rising Costs of Type 2 Diabetes in Australia: Projections From the Fremantle Diabetes Study. Intern Med J 36(3):151161

Delerive, P., Fruchart, J.C., and Staeals, B. (2001). Peroxisome Proliferator-activated Receptors in Inflammation control. J. Endocrinol. 169(3):453-459

Evan, D.R., and Bruce, M.S. (2001). PPARy: A Nuclear Regulator of Metabolism, Differentiation and Cell Growth. The Journal of Biological Chemistry 276(41):37731-37734

Gale, E.A.M. (2001). Lessons from the Glitazones: A Story of Drug Development. Lancet 357:1870-1875

Grey, A., Bolland, M., and Gamble, G. (2007). The peroxisome proliferators-activated receptor- $\gamma$ agonist rosiglitazone decreases bone formation and bone mineral density in healthy postmenopausal women: A randomized, controlled trial. J. Clin. Endocrinol. Metab. 92:1305-1310

Goldstein, B.J. (2003). Insulin Resistance: From Benign to type 2 diabetes mellitus. Rev. Cardiovasc. Med. 4(Suppl 6):S3-S10

Higa, M., Zhou, Y.T., Ravazzola, M., Baetens, D., Orci, L., Unger, R.H. (1999). Troglitazone Prevents Mitochondrial Alterations, beta Cell Destruction and Diabetes in Obese Prediabetic Rats. Proc. Natl. Acad. Sci. USA 96(20):11513-11518

Hsueh, W.A., and Law, R.E. (2001). PPARY and Arteriosclerosis: Effect on Cell Growth and Movement. Arterioscler. Thromb. Vasc. Biol. 21(12):1891-1895

Hsueh, W.A., and Bruemmer, D. (2004). Peroxisome proliferator-Activated Receptor $\mathrm{Y}$ : Implications for cardiovascular Diseases. Hypertension 43(part 2):297-305

Home, P.D., Pocock, S.J., Beck-Nielsen, H., Curtis, P.S., Gomis, R., Hanefeld, M., Jones, N.P., Komajda, M., and McMurray, J.J.V. (2007). RECORD study group. Rosiglitazone evaluated for cardiovascular outcomes: an interim analysis. $N$ Engl J Med 357:28-38

Hotamisligil, G.S. (2005). Role of Endoplasmic Reticulum stress and c-Jun $\mathrm{NH2}$-terminal kinase pathways in inflammation and origin of obesity and diabetes. Diabetes 54(2):S73-8

International Diabetes Federation (2009). Diabetes Atlas. Available http://www.diabetesatlas.org/content/what-isdiabetes accessed on 31/12/09

Isa, S.A. (2011). The Impact of Natural and Synthetic PPARY ligands on ER stress and unfolded protein response PhD Thesis University of Wales Institute Cardiff

Janssen, I., Katzmarzyk, P.T., and Ross, R. (2002). Body mass index, waist circumference and health risk: evidence in support of current National Institute of Health Guidelines. Arch. Intern. Med. 162(18):20742079

Juhl, C.B., Hollingdal, M., Porksen, N., Prange, A., lonnqvist, F., and Schmitz, O. (2003). Influence of Rosiglitazone treatment on $\beta$-cell function in type 2 diabetes: Evidence of an increased ability of glucose to entrain high-frequency insulin pulsatility. $J$. Endocrinol. Metab. 88:3794-3800

Kass, G.E., Orrenius, S. (1999). Calcium signalling and cytotoxicity. Environ. Health Perspect. 107:25-35
Kang, P.M., and Izumo, S. (2000). Apoptosis and Heart failure. A critical review of the literature. Circ. Res. 86(11): $1107-1113$

Kahn, S.E., Haffner, S.M., Heise, M.A., Herman, W.H., Holman, R.R., Jones, N.P., Kravitz, B.G., Lachin, J.M., O'Neill, M., Zinman, B., and Viberti, G. (2006). Glycaemic durability of rosiglitazone, metformin or glyburide monotherapy. N. Eng. J. Med. 355(23):2427-2443.

Kahn, C., Chen, L., and Cohen, S. (2000). Unraveling the Mechanism of Action of Thiazolidinediones J. Clin. Invest. 106(11):1305-1307

Kruszynska, Y.T., Yu, J.G., Olefsky, J.M., and Sobel, B.E. (2000). Effects of Troglitazone on Blood Concentrations of Plasminogen Activator inhibitor 1 in patients with Type 2 diabetes and in Lean and Obese normal subjects. Diabetes 49(4):633-639

Kliewer, S.A., Lenhard, J.M., Wilson, T.M., Patel, I., Morris, D.C., Lehmann, J.M. (1995). A prostaglandin ]" Metabolite binds peroxisome proliferatorsactivated receptor $\mathrm{Y}$ and promotes adipocyte differentiation. Cel/ 83:803-812

Lebovitz, H.E., and Banerji, M.A. (2001). Insulin Resistance and its Treatment by Thiazolidinediones. Recent. Prog. Hormone Res. 56:265-294

Maggs, D.G., Buchanan, T.A., Burant, C.F., Clines, G., Gumbiner, B., Hsueh, W.A., Inzucchi, S., Kelley, D., Nolan, J., Olefsky, J.M., Polonsky, K.S., Silver, D., Valiquett, T.R., and Shulman, G.I (1998). Metabolic Effects of Troglitazone Monotherapy in Type 2 Diabetes Mellitus. A Randomised Double-Blind, Placebo-Controlled Trial. Annals of Internal Medicine 128(3):176-185

Marx, N., Froehlich, J., Siam, L., Ittner, J., Wierse, G., Schmidt, A., Scharnagl, H., Hombach, V., and Koenig, W. (2003). Antidiabetic PPAR $\gamma$ Activator Rosiglitazone Reduces MMP-9 Serum Levels in Type 2 Diabetic Patients With Coronary Artery Disease. Arterioscler. Thromb. Vasc. Biol. 23(2):283-288

Marx, N., Libby, P., and Plutzky, J. (2001). Peroxisome Proliferator-Activated Receptors (PPARs) and Their Role in the Vessel wall: Possible Mediators of Cardiovascular Risk? J. Cardiovasc. Risk 8(4):203210

Mudaliar, S. (2007). New Frontiers in the Management of Type 2 Diabetes. Indian J Med Res 125(3):275-296

Nagy, L., Tontonoz, P., Alvarez, J.G., Chen, H., and Evans, R. (1998). Oxidized LDL regulates macrophage gene expression through ligand activation of PPARgamma. Cell93(2):229-240

Nathan, D.M., Buse, J.B., Davidson, M.B., Heine, R.J., Holman, R.R., Sherwin, R., Zinman, B. (2006). Professional Practice Committee, American Diabetes Association, European Association for the Study of Diabetes. Management of Hyperglycemia in Type 2 Diabetes: A consensus Algorithm for the Initiation and Adjustment of Therapy. A Consensus Statement from the American Diabetes Association and the European Association for the Study of Diabetes. Diabetologia 49(8): 1711-1721

Nissen, S.E., and Wolski, K. (2007). Effect of Rosiglitazone on the risk of myocardial infarction and death from cardiovascular causes. N. Eng. J. Med. 356(24):2457-2471 
Niemi, M., Backman, J.T., Granfors, M., Laitila, J., Neuvonen, M., and Neuvonen, P.J. (2003). Gemfibrozil considerably increases the plasma concentrations of rosiglitazone. Diabetologia 46(10): 1319-1323

Okada, K., Minamino, T., Tsukamoto, Y., Liao, Y., Tsukamoto, O., Takashima, S., Hirata, A., Fujita, M., Nagamachi, Y., Nakatani, T., Yutani, C., Ozawa, K., Ogawa, S., Tomoike, H., Hori, M., and Kitakaze, M. (2004). Prolonged endoplasmic reticulum stress in hypertrophic and failing heart after aortic constriction: possible contribution of endoplasmic reticulum stress to cardiac myocyte apoptosis. Circulation 110(6):705-712

Olefsky, J.M. (2000). Treatment of Insulin Resistance with Peroxisome Proliferator-Activated Receptor $Y$ Agonist. The Journal of Clinical Investigation 106(4):467-472

Olefsky, J.M., and Saltiel, A.R. (2000). PPAR gamma and the Treatment of Insulin Resistance. Trends Endocrin Metab 11(9):362-368

Patil, C., Walter, P. (2001). Intracellular signalling from the endoplasmic reticulum to the nucleus: the unfolded protein response in yeast and mammals. Curr. Opin. Cell. Biol. 13:349-355

Raskin, P., Rendell, M., Riddle, M.C., Dole, J.F., Freed, M.I., and Rosenstock, J. (2001). A Randomised Trial of Rosiglitazone Therapy in Patients with Inadequately Controlled Insulin-Treated Type Diabetes. Diabetes Care 24:1226-1232

Randriamboavonjy, V., Pitrosch, F., Bolck, B., Schwinger, R.H., Dixit, M., Badenhoop, K., Cohen, R.A., Busse R., and Fleming, I. (2008). Platelet sarcoplasmic endoplasmic reticulum $\mathrm{Ca} 2+$ Atpase and mu-caplain activity are altered in type 2 diabetes and restored by rosiglitazone Circ 117(1):52-60.

Rexrode, K.M., Carey, V.J., Hennekens, C.H., Walters, E.E., Colditz, G.A., Stampfer, M.J., Willett, W.C., and Manson, J.E. (1998). Abdominal Adiposity and Coronary Hearth Disease in Women. JAMA 280(21): 1843-1848

Ron, D., and Walter, P. (2007). Signal integration in the endoplasmic reticulum unfolded protein response. Nat. Rev. Mol. Cell. Biol. 8:519-529

Rosen, C.J. (2010). Revisiting the Rosiglitazne story lessons learned. New England Journal of Medicine 363(9):803-806

Seidell, J.C., Verschuren, W.M., van Leer, E.M., and Kromhout, D. (1996). Overweight, Underweight and Mortality. A Prospective Study of 48,287 men and women. Arch. Intern. Med. 156(9):958-963

Singh, S., Loke, Y.K., and Furberg, C.D. (2007). Longterm Risk of Cardiovascular Events with Rosiglitazone: A Meta-analysis. JAMA 298(10):11891195

Smith, S.A. (2003). Central Role of Adipocyte in InsulinSensitising and Cardiovascular Risk Modifying Actions of Thiazolidinediones. Biochemie 85:1219-1230

Shah, R.D., Gonzales, F., Golez, E., Augustin, D., Caudillo, S., Abbott, A., Morello, J., McDonough, P.M., Paolini, P.J., and Shubeita, H.E. (2004). The antidiabetic agent rosiglitazone upregulates SERCA2 and enhances TNF-a- and LPS-induced NF-KB- dependent transcription and TNF-a-induced IL- 6 secretion in ventricular myocytes. Cell Physiol. Biochem, 15:41-50.

Singh, N., Webb, R., Adams, R., Evans, S., Al-Mosawi, A., Evans, M., Roberts, A.W., and Thomas, A.W. (2005). The PPAR-y activator, Rosiglitazone, inhibits actin polymerisation in monocytes: Involvement of Akt and intracellular calcium. Biochem. Biophys. Res. Comm. 333(2):455-462.

Soroceanu, M.A., Miao, D., Bai, X., Su, H., Goltzman, D., and Karaplis, A.C. (2004). Rosiglitazone Impacts Negatively on Bone by Promoting Osteoblast/Osteocyte Apoptosis. Journal of Endocrinology 183:203-216

Stein, C.J., and Colditz, G.A. (2004). The Epidemic of Obesity. J. Clin. Endocrinol. Metab. 89(6):25222525.

St John Sutton, M., Rendell, M., Dandonna, P., Dole, J.F., Murphy, K., Patwardhan, R., Patel, J., and Freed, M. (2002). A Comparison of the Effects of Rosiglitazone and Glyburide on Cardiovascular Function and Glycemic Control in Patients with Type 2 Diabetes. Diabetes Care 25(11):2058-2064

Suh, N., Wang, Y., Honda, T., Gribble, G.W., Dmitrovsky, E., Hickey, W.F., Mave, R.A., Place, A.E., Porter, D.M., Spinella, M.J., Williams, C.R., Wu, G., Dannenberg, A.J., Flanders, K.C., Letterio, J.J., Mangelsdorf, D.J., Nathan, C.F., Nguyen, L., Porter, W.W., Ren, R.F., Roberts, A.B., Rohe, N.S., Subbaramaiah, K., and Sporn, M.B. (1999). A Novel Synthetic Oleanane Triterpenoid, 2-Cyano-3, 12dioxoolean-1,9-dien-28-oic acid, with Potent Differentiating, Anti-proliferative and Antiinflammatory Activity. Cancer Research 59:336-341

Szegezdi, E., Logue, S.E., Gorman, A.M., and Samali, A. (2006). Mediators of endoplasmic reticulum stressinduced apoptosis. EMBO reports 7(9):880-885

Tai, E.S., Lau, T.N., Ho, S.C., Fok, A.C., and Tan, C.E. (2000). Body Fat Distribution and Cardiovascular Risk in Normal Weight Women. Associations with Insulin Resistance, Lipids and Plasma Leptin. Int. J. Obesity Relat. Metab. Disord. 24(6):751-757

Tontonoz, P., Hu, E., Graves, R.A., Budavari, A.I, and Spiegelman, B.M. (1994). mPPAR gamma 2: issueSpecific Regulator of an Adipocyte Enhancer. Genes Development 8(10):1224-1234

Viberti, G. (2005). Thiazolidinediones-benefits on microvascular complications of type 2 diabetes. $\mathrm{J}$. Diabetes Complications 19(3):168-177

Watala, C., Boncler, M., and Gresner, P. (2005). Blood Platelet abnormalities and Pharmacological modulation of platelet reactivity in patients with diabetes mellitus. Pharmacol. Rep. 57:42-58

WHO. Obesity and Diabetes. World Health Organisation, 2002

Yach, D., Stuckler, D., and Brownell, KD. (2006). Epidemiologic and Economic Consequences of the Global Epidemics of Obesity and Diabetes. Nat Med 12(1):62-66

Zhang, K., and Kaufman, R.J. (2008). From endoplasmicreticulum stress to the inflammatory response. Nature 454(7203):455-462 